\title{
Assessment of Knowledge and Attitude of Tuberculosis Patients in Direct Observation Therapy Program towards Multidrug-Resistant Tuberculosis in Addis Ababa, Ethiopia: A Cross-Sectional Study
}

\author{
Firew Tadesse Kusheno ${ }^{10},{ }^{1}$ Teklehaimanot Mezgebe Nguse, \\ and Gebremedhin Beedemariam Gebretekle $\mathbb{D D}^{3}$ \\ ${ }^{1}$ ICAP-Ethiopia, Addis Ababa, Ethiopia \\ ${ }^{2}$ Departments of Radiography, School of Medicine, College of Health Sciences, Addis Ababa University, Ethiopia \\ ${ }^{3}$ Department of Pharmaceutics and Social Pharmacy, School of Pharmacy, College of Health Sciences, \\ Addis Ababa University, Ethiopia
}

Correspondence should be addressed to Firew Tadesse Kusheno; firewtadesse.kusheno81@gmail.com

Received 6 December 2019; Revised 20 April 2020; Accepted 28 May 2020; Published 8 June 2020

Academic Editor: Vincent Jarlier

Copyright (C) 2020 Firew Tadesse Kusheno et al. This is an open access article distributed under the Creative Commons Attribution License, which permits unrestricted use, distribution, and reproduction in any medium, provided the original work is properly cited.

\begin{abstract}
Background. Multidrug-resistant tuberculosis (MDR-TB) is becoming a major challenge of tuberculosis (TB) control program globally but more serious in developing countries like Ethiopia. In 2013, a survey result showed that in Ethiopia, tuberculosis patients from new cases and retreatment cases had resistance to at least isoniazid and rifampicin with a significant increase over time. Inadequate knowledge and wrong perception about MDR-TB by patients were detrimental to TB control programs. The study aimed at assessing the knowledge and attitude of TB patients of direct observation therapy program towards multidrugresistant tuberculosis in health centres of Addis Ababa, Ethiopia. Methods. A cross-sectional study was conducted in 10 health centres of Addis Ababa which were selected by simple random sampling technique. A total of $422 \mathrm{~TB}$ patients were included in the study, and participants from each health centres were taken proportional to the number of clients in each health centres. Data was entered and analyzed using SPSS version 20. Association between outcome and independent variables was explored using logistic regression. Results. The level of knowledge of TB patients about MDR-TB was poor and only $55.0 \%$ of TB patients attained good overall knowledge. A significant association was found between good knowledge and attending tertiary level of education $(\mathrm{AOR}=4.3,95 \% \mathrm{CI}=1.9,9.8)$, gender $(\mathrm{AOR}=1.62,95 \% \mathrm{CI}=1.1,2.4)$, income of respondents' family $(\mathrm{OR}=0.4,95 \%$ $\mathrm{CI}=0.2,0.9)$, and sleeping practice $(\mathrm{AOR}=8.0,95 \% \mathrm{CI}=4.0,15.7)$. Nearly three-fourths $(73.5 \%)$ of $\mathrm{TB}$ patients had a favourable attitude towards MDR-TB. Occupational status $(\mathrm{AOR}=4.4,95 \% \mathrm{CI}=2.5,7.6)$ and sleeping practices $(\mathrm{AOR}=2.4$, $95 \% \mathrm{CI}=1.2,5.0)$ were significantly associated with the attitude of the TB patients. Conclusions. Knowledge of TB patients toward MDR-TB was poor. Although a large proportion of patients had a favourable attitude, it still needs to be improved. Hence, efforts should be made to implementing health education to improve awareness of TB patients about MDR-TB.
\end{abstract}

\section{Introduction}

Tuberculosis (TB) is a leading cause of morbidity and mortality of worldwide, accounting for about 9.6 million new cases and 1.5 million deaths annually [1]. In 2015, there were an estimated 10.4 million new TB cases and 1.4 mil- lion TB deaths worldwide. The higher burden of TB disease is observed among men, with ratios ranging from 1.5 (in Ethiopia) compared to 6.0 (in Rwanda) for smearpositive TB patients, and also from 1.2 (in Ethiopia) compared to 4.5 (in Vietnam) for bacteriologically confirmed TB patients [2]. The proportion was highest in the WHO 
African Region countries and exceeded 50\% in parts of southern Africa [2]. Africa accounted for about $26 \%$ of the incident $\mathrm{TB}$ cases, with the highest rates of incident cases and deaths [2]. Ethiopia is one of the $30 \mathrm{High}$ TB Burden Countries in the world with estimated TB incident cases of 192 per 100,000 in 2015 (WHO, 2016). Furthermore, the issue of poverty as one of the major risk factors for developing TB places Ethiopia as a high-risk environment [3].

The disease burden caused by TB is falling globally, in all WHO regions, and in most countries, but not fast enough to reach the first (2020) milestones of the End TB Strategy [4]. Nonetheless, these efforts have been jeopardized by multidrug-resistant TB (MDR-TB), and MDR$\mathrm{TB}$ is caused by an organism that is resistant to at least isoniazid and rifampin which are the two most potent TB drugs [4]. In 2015, there were an estimated 480,000 new cases of multidrug-resistant TB (MDR-TB) and an additional 100,000 people with rifampicin-resistant $\mathrm{TB}$ (RR-TB) who were also newly eligible for MDR-TB treatment (WHO, 2016) [2]. According to the WHO report, Ethiopia also had an estimated 1700 and 550 MDR-TB cases among notified new and retreatment pulmonary $\mathrm{TB}$ cases in 2011, respectively [5]. A 2013 survey result showed that $2.3 \%$ of new cases and $17.8 \%$ of retreatment cases were resistant to at least rifampicin and isoniazid with a significant increase in Ethiopia [6]. As a result, drug-resistant TB has become a major challenge of the TB control program in Ethiopia [7].

Inadequate anti-TB treatment is an important factor that can contribute to the development of drug-resistant TB strains [8]. The factors causing inadequate anti-TB treatment can be grouped into health system factors (inadequate training and drug stock-outs), drug factors (high pill burden and long duration of treatment), and patient factors (poor adherence, mal-absorption, and adverse drug effects) [9]. Studies have identified that there are misconceptions and limitations of knowledge about MDR-TB among TB patients [10]. Also in this study, $150(35.5 \%)$ of TB patients agree that MDRTB is treated by praying or holy water, 195 (46.2\%) agreed that people get MDR-TB through drinking of alcohol, and 102 (24\%) of TB patients agreed that taking traditional medicine can cure of MDR-TB. In Mongolia, only $31.8 \%$ of the respondents knew that $\mathrm{TB}$ is not heritable, and $22.7 \%$ were aware of complications and high chances of spreading the infection to family members in case of not taking treatment or discontinue the treatment [11].

The lack of knowledge about the cause, mode of transmission, and symptoms, as well as appropriate treatment of TB within communities also contribute to poor adherence to TB treatment and/or long delay in diagnosis [12]. This in return will contribute to the increasing emergence of MDRTB and finally leaving patients with minimal choices [13]. To the best of our knowledge, no study has been conducted in Ethiopia to assess the level of knowledge and attitude of TB patients about MDR-TB. Hence, the purpose of this study was to assess the knowledge and attitude of TB patients of direct observation therapy program towards MDR-TB in health centres of Addis Ababa, Ethiopia. The findings could be used by policymakers to designing appropriate prevention and control strategies.

\section{Methods}

2.1. Study Area. The study was conducted in public health centres in Addis Ababa, Ethiopia. Addis Ababa is the capital city of Ethiopia and the political hub of Africa. Administratively, the city is divided into 10 subcities and 116 Woredas. It has a total area of 54,000 hectares, and the total population is 3,122,000 of which 1,634,403 (52.6\%) of them are females (Central Statistical Agency Ethiopia), Population Projection of Ethiopia for all regions at Woreda level from 2014-2017 Addis Ababa, Ethiopia, 2013 [14]. The city administration has a total of 93 health centres and 11 public hospitals [7].

2.2. Study Design. A facility-based cross-sectional study was conducted in public health centres of Addis Ababa between April 20 and May 30, 2016. TB Patients under the direct observation therapy (DOT) program in all health facilities of Addis Ababa were the source of the study. All TB patients, who attended the DOT program in public health centres between April 20 and May 30, 2016, were sources of the data for the study. However, all TB patients who attended the DOT program in hospitals and private health institutions were excluded from the study.

The sample size was determined by using a single proportion formula [15]. Due to absence of research related to knowledge, nonchalant attitude toward MDR-TB among the DOT program in Ethiopia, and difficulties in getting maximum sample size, it was assumed that about $50 \%$ of TB patients had good knowledge and favourable attitude toward MDR-TB. The margin of error was assumed to be $5 \%$ with a $95 \%$ confidence interval. Thus, considering a $10 \%$ none and inappropriate response rate, a total of 422 TB patients were included in this study.

From the ten subcities in Addis Ababa, five subcities were selected by simple random sampling method. Then, a total of ten health centres, two from each subcity, were selected using a random sampling method. Finally, the number of TB patients to be recruited from each health centres were decided based on the size of patients attending the DOT program, and individual participants from each health facility were selected using a random sampling method.

2.3. Data Collection and Management. Data were collected using semistructured questionnaires adopted from different scholars and modified based on the current research $[6,7$, 9, 10]. The questionnaire had three parts. The first part was designed to elicit the sociodemographic characteristics of each study participant, while the second part was related to knowledge and twelve questions were provided. In the third part, attitudes of study participants were assessed by 12 questions, which focused on symptoms, transmission, prevention, and treatment of MDR-TB. The dependent variables of the study were knowledge and attitude of TB patients towards MDR-TB. Gender, age, educational status, marital status, occupational status, overcrowding (family size), use of ventilation system, and average monthly 
income of respondents were identified as an independent variable of the study.

The data were collected by face-to-face interview and ten health professionals; 5 health officers, 3 Bachelor of Science, and 2 diploma nurses who were not working in the selected health facilities were recruited as data collectors. Before the actual data collection, one-day training focused on the aim of the study, and a detailed review of the tool was given to all data collectors. The questionnaires were preadministered in $22(5 \%)$ of TB patients in one of the health centres which was not included in the actual study and modification was made accordingly. Furthermore, adequate supervision and follow up was done by the supervisors to maximize the quality of the data collected.

2.4. Data Entry and Analysis. Data were entered and cleaned using EPI-info version 3.5.1 and exported to SPSS version 20.0 for analysis. Simple descriptive statistics including mean, percentage, and standard deviations were computed to summarize categorical variables. Possible associations between the variable of interest were explored using logistic regression as significant at $p<0.05$.

Giving correct answers earned a score of 1 but if the response is wrong, then it attracts a score of 0 . Knowledge and attitude for individuals were calculated and summarized to give total score. Sum up to give their total score. In this study, knowledge was measured based on the ability of patients to correctly identify and respond to cause, mode of transmission and factors related to transmission, signs and symptoms, and possible ways of prevention of TB and MDR-TB treatment. Then, knowledge aspects were categorized into good and poor score if it is equal or above the mean and below the mean, respectively. The attitude was measured by feelings towards the cause, treatment, and about the follow-up and felling when others knew that you have TB. Each had one point if correctly answered. The favorability and unfavorability classification was based on each mean value. Participants who scored equal or above the mean were considered favourable attitude, if it is below considered as unfavourable attitude.

2.5. Ethical Consideration. The study was approved by the Addis Ababa City Administration Health Bureau (ref. no. A/A/H/6381/227) and Africa Medical College ethics review board. Besides, permission was sought from the subcities and respective health centres. Finally, informed verbal consent was obtained from all participants after explaining the purpose of the study and informing that their response will be kept confidential. Questionnaires were coded, and collected data was locked in a lockable cabinet to maintain the confidentiality of the information obtained.

\section{Results}

3.1. Sociodemographic Profile of the Studied Participants. A total of $422 \mathrm{~TB}$ patients were interviewed in this study. Among them, 217 were male which contributed 51.4\% for the total analysis, and $50.2 \%$ of them were ever married. More than two-thirds (67.3\%) of patients were less than or
TABLE 1: Sociodemographic and socioeconomic profiles of TB patients in Addis Ababa, Ethiopia, $2016(N=422)$.

\begin{tabular}{|c|c|}
\hline Characteristics & $n(\%)$ \\
\hline \multicolumn{2}{|l|}{ Age } \\
\hline$\leq 34$ years & $280(67.3)$ \\
\hline $35-54$ years & $115(27.6)$ \\
\hline$>54$ years & $21(5.0)$ \\
\hline \multicolumn{2}{|l|}{ Educational status } \\
\hline Illiterate & $40(9.5)$ \\
\hline Primary level (1 to 8 grade) & $147(34.8)$ \\
\hline Secondary level (9 to12 grade) & $95(22.5)$ \\
\hline Tertiary level & $140(33.2)$ \\
\hline \multicolumn{2}{|l|}{ Marital status } \\
\hline Ever married & $214(50.2)$ \\
\hline Never married & $207(49.8)$ \\
\hline \multicolumn{2}{|l|}{ Occupational status } \\
\hline Unemployed & $129(30.6)$ \\
\hline Employed & $293(69.4)$ \\
\hline \multicolumn{2}{|c|}{ Average monthly income of respondents' family (ETB) } \\
\hline$<585$ & $175(41.7)$ \\
\hline $586-1650$ & $58(13.8)$ \\
\hline $1651-3145$ & $82(19.5)$ \\
\hline$\geq 3146$ & $105(25.0)$ \\
\hline \multicolumn{2}{|c|}{ Number of family or friends living with TB patients } \\
\hline No one with me & $102(24.2)$ \\
\hline 2-4 family/friend's size & $244(57.8)$ \\
\hline$\geq 5$ family/friend's size & $76(18.0)$ \\
\hline \multicolumn{2}{|l|}{ Sleeping practice of $\mathrm{TB}$ patients } \\
\hline Alone and separate room & $189(44.8)$ \\
\hline Alone but not separate room & $116(27.5)$ \\
\hline Use one bed with others in one room & $117(27.7)$ \\
\hline
\end{tabular}

equal to 34 years, and the mean age of respondents was $32.12 \pm 11.0$ years. The interviewed people in terms of age ranged from 13 to 70 years, as shown in Table 1.

Concerning their educational status, the majority of 147 $(34.8 \%)$ of the TB patients attended primary level followed by the tertiary level of education which accounted for 140 (33.2\%). Regarding their average monthly family income, $175(41.5 \%)$ of them had only $\leq 585$ ETB. The study also revealed that 293(69.4\%) of the TB patients were employed. Concerning their living condition, 76 (18\%) of them were living with five or more of his/her family members or friends. More than one-fourth (27.7\%) of TB patients were sharing one bed with a member of the family or friend in one room (Table 1).

From the 422 TB patients, 134 (33.0\%) never heard about MDR-TB at all, while 178 (62.7\%) heard about MDR-TB from health workers. Regarding the definition of MDR-TB, $68(16.1 \%)$ of TB patients said they know the meaning of MDR-TB as TB disease caused by a strain of mycobacterium tuberculosis that is resistant to at least two (Isoniazid and Rifampicin) anti-TB drugs. On the other hand, 70 (16.6\%) of TB patients did not know the meaning of MDR-TB. 
TABLE 2: Frequency and percent of knowledge measuring variables of TB patients, Addis Ababa, Ethiopia, $2016(N=422)$.

\begin{tabular}{|c|c|}
\hline Characteristics & Frequency (\%) \\
\hline \multicolumn{2}{|l|}{ Where have you heard about MDR-TB?* } \\
\hline Heard from health workers & $178(42.2)$ \\
\hline Heard from mass media (television, radio, and taps) & $94(22.3)$ \\
\hline Heard from printed or electronic media & $29(6.9)$ \\
\hline Heard from friends, family, and school & $49(11.6)$ \\
\hline \multicolumn{2}{|l|}{ What are the possible consequences of defaulting on TB treatment?* } \\
\hline The TB is not cured and it will come back again & $301(71.3)$ \\
\hline TB patient may die & $171(40.5)$ \\
\hline Patient may develop multidrug-resistant TB (MDR-TB) & $144(34.1)$ \\
\hline Longer duration of absence from patient's job (source of income) & $61(14.5)$ \\
\hline Not know & $9(2.1)$ \\
\hline \multicolumn{2}{|l|}{ What is the meaning of multidrug resistance tuberculosis?* } \\
\hline Tuberculosis disease caused by a strain of TB that is resistant to at least two anti-TB drugs. & $68(16.1)$ \\
\hline Tuberculosis disease that is resistant to one anti-TB drug & $77(18.2)$ \\
\hline Form of $\mathrm{TB}$ that requires treatment with expensive drugs & $60(14.2)$ \\
\hline Form of TB that requires treatment which gives more side effects & $40(9.5)$ \\
\hline Resistance due to default of anti TB or not complete anti-TB drug. & $193(45.7)$ \\
\hline Not know meaning of MDR-TB. & $70(16.6)$ \\
\hline \multicolumn{2}{|l|}{ What is the cause of multidrug resistance tuberculosis? } \\
\hline Bacteria & $212(50.2)$ \\
\hline Virus and not know cause & $66(15.7)$ \\
\hline From GOD acrimony/penalty & $27(6.4)$ \\
\hline Cold weather & $151(35.3)$ \\
\hline \multicolumn{2}{|l|}{ What are the common transmission ways of MDR-TB? } \\
\hline Person to person (inhalation of infected droplet nuclei during coughing, sneezing & $357(85.5)$ \\
\hline By sexual contact & $38(9.0)$ \\
\hline By blood contact and (others) & $42(9.9)$ \\
\hline \multicolumn{2}{|l|}{ What are the signs and symptom of tuberculosis?* } \\
\hline Long-lasting cough (two weeks and greater) & $371(87.9)$ \\
\hline Persistent fever & $193(45.7)$ \\
\hline Loss of weight & $192(45.5)$ \\
\hline Hemoptysis & $208(49.3)$ \\
\hline Night sweating & $183(43.4)$ \\
\hline Chest pain & $90(21.3)$ \\
\hline Loss of appetite & $120(28.4)$ \\
\hline Others like swelling, weakness, rheumatism & $18(4.3)$ \\
\hline \multicolumn{2}{|l|}{ What is the duration of treatment of MDR-TB? } \\
\hline Duration of treatment of MDR-TB (6 months and 8 months) & $136(32.3)$ \\
\hline Duration of treatment of MDR-TB $(18,20$, and 24 months $)$ & $217(51.3)$ \\
\hline Not know duration of treatment of MDR-TB & $69(16.4)$ \\
\hline \multicolumn{2}{|l|}{ Why was it important to complete treatment of tuberculosis?* } \\
\hline TB patients to be cured & $386(91.5)$ \\
\hline Repeated interruption of treatment leads to drug resistance and treatment failure & $56(13.3)$ \\
\hline It control/prevent from transmission of $\mathrm{TB}$ & $136(32.3)$ \\
\hline If the treatment is not completed, the TB has a high chance of coming back and untreated TB can result in death & $113(26.8)$ \\
\hline \multicolumn{2}{|l|}{ Who is high risk to develop MDR-TB?* } \\
\hline Retreatment regimen failure TB patient & $194(46.0)$ \\
\hline Close contact history with a known MDR-TB patient & $142(33.6)$ \\
\hline
\end{tabular}


TABLE 2: Continued.

\begin{tabular}{lc}
\hline Characteristics & Frequency (\%) \\
\hline New treatment regimen failure TB patient & $137(32.5)$ \\
Retreatment TB patients [e.g., return after default, relapse) & $97(23.0)$ \\
Under five children are high risk & $102(24.2)$ \\
People living with HIV/ADIS & $89(21.1)$ \\
Not know who was high risk to develop MDR-TB & $53(12.6)$ \\
Others like health workers, stopped TB treatment drugs & $7(1.7)$ \\
Was it possible to control the transmission of MDR TB? & $321(76.1)$ \\
Yes & $101(24)$ \\
No & \\
How can it is possible to prevent MDR-TB?* & 266 (63) \\
Completing all TB cases treatment properly without defaulting & $139(33)$ \\
Cover mouth and nose when cough, sneezing, laughing and talking & $144(34.1)$ \\
Keep the windows and doors opened & $87(20.6)$ \\
By using the appropriate treatment regimen/drug for all TB cases. & $6(1.4)$ \\
Which group of people do you think affected by MDR-TB mostly? & $113(26.8)$ \\
Rich & $303(71.8)$ \\
Poor & \\
Anybody
\end{tabular}

* indicates percentage sum was more than $100 \%$ because of multiple responses and think that there are missed value in variables.

Regarding the high-risk group of developing MDR-TB, 53 (12.6\%) of TB patients did not know who was at high risk to develop MDR-TB. Respondents were also asked on the possible consequences of defaulting anti-TB treatment, and $146(34.1 \%)$ of TB patients correctly mentioned that TB patients may develop MDR-TB, and 56 (13.3\%) of TB patients believed that repeated interruption of treatment leads to more drug resistance and treatment failure. One hundred and thirteen (26.8\%) respondents reported that poor people are at a higher risk of developing MDR-TB compared to wealthy people (Table 2).

Regarding the causes of MDR-TB, 212 (50.2\%) of TB patients said that the causes of MDR-TB are bacteria or germs that cannot be seen with the naked eyes, while 151 (35.8\%) respondents said that the causes of MDRTB were cold weathers, God acrimony/penalty and virus, respectively. Overall, almost half (49.8\%) of TB patients did not know the exact causes of MDR-TB. Concerning transmission of MDR-TB, 361 (85.5\%) of the TB patients mentioned that through inhalation of infected droplet nuclei during coughing, sneezing, and talking was the way of transmission, 38 (9\%) said that sexual contact, while 42 (9.9\%) said it can be transmitted through blood contact. Regarding the duration of treatment of MDR-TB, $217(51.3 \%) \mathrm{TB}$ patients knew the duration of treatment of MDR-TBs which is between 18 to 24 months, and $69(16.4 \%)$ of TB patients did not know the duration of treatment of MDR-TB. Regarding the possible ways to control the transmission of MDR-TB, 101 (24.0\%) of TB patients reported that it was not possible to control the transmission of MDR-TB while the rest of the respondents knew one or more controlling mechanisms from the given choices (Table 2).
TB patients' overall knowledge of MDR-TB was evaluated by summarizing the twelve questions, and the study showed that the mean knowledge scored was $6.0 \pm 0.5$. The study found that $190(45.0 \%)$ of patients scored below the mean, and they had poor knowledge about MDR-TB. Multivariate analysis showed a significant association of overall knowledge with an educational status where those with tertiary level educational status had more likely of good knowledge $(\mathrm{AOR}=4.3,95 \% \mathrm{CI}=1.9,9.8)$ compared to the illiterate patients. Male TB patients were 1.6 times more likely to have good knowledge than females. Knowledge of TB patients was also significantly associated with the sleeping practice where $\mathrm{TB}$ patients sleeping alone in a separate room $(\mathrm{AOR}=8.0$, $95 \% \mathrm{CI}=4.0,15.7)$ and sleeping alone but not separate room $(\mathrm{AOR}=5.8,95 \% \mathrm{CI}=2.9,11.2)$ were more likely to have good knowledge compared to those who were sleeping in one bed with his/her family or friends. Respondents whose family average monthly income less than 585 ETB had poor overall knowledge ( $\mathrm{AOR}=0.4,95 \% \mathrm{CI}=0.2,0.9)$ compared with respondents whose family average monthly income greater than or equal to 3146 ETB (Table 3). On the other hand, multivariate analysis showed that age, marital status, family size, and occupational status of respondents were not significantly associated with knowledge of patients about MDR-TB (Table 3).

3.2. TB Patients Overall Attitude towards MDR-TB and Its Associated Factors. All respondents were asked about their attitudes towards MDR-TB, as presented in Table 4. More than one-third $(37.9 \%)$ of TB patients agreed that they had fear of discrimination and $150(35.5 \%)$ of the respondents agreed that MDR-TB can be treated by praying or by holy 
TABLE 3: TB patients' overall knowledge and associated factors on MDR-TB in Addis Ababa, Ethiopia, $2016(N=422)$.

\begin{tabular}{|c|c|c|c|c|}
\hline \multirow[t]{2}{*}{ Characteristics } & \multicolumn{2}{|c|}{$\begin{array}{l}\text { Overall knowledge } \\
\qquad(n(\%))\end{array}$} & \multicolumn{2}{|c|}{ Odds ratio } \\
\hline & Poor & Good & Crude (COR) & Adjusted (AOR) \\
\hline \multicolumn{5}{|l|}{ Sex } \\
\hline Male & $84(19.9)$ & $133(31.5)$ & $1.7(1.2,2.5)$ & $1.62(1.1,2.4)^{*}$ \\
\hline Female & $106(25.1)$ & $99(23.5)$ & 1.0 & 1.0 \\
\hline \multicolumn{5}{|l|}{ Age (years) } \\
\hline$\leq 34$ & $124(29.4)$ & $156(36.9)$ & 1.0 & 1.0 \\
\hline $35-54$ & $55(13.0)$ & $60(14.2)$ & $0.87(0.56,1.34)$ & $0.81(0.5,1.3)$ \\
\hline$\geq 55$ & $8(1.9)$ & $13(3.1)$ & $1.3(0.52,3.22)$ & $1.2(0.5,2.9)$ \\
\hline \multicolumn{5}{|l|}{ Marital status } \\
\hline Never married & $92(18.7)$ & $115(31.1)$ & $1.1(0.7,1.55)$ & $0.9(0.6,1.5)$ \\
\hline Ever married & $98(26.3)$ & $116(23.9)$ & 1.0 & 1.0 \\
\hline \multicolumn{5}{|l|}{ Educational status } \\
\hline None (illiterate) & $24(5.7)$ & $16(3.8)$ & 1.0 & 1.0 \\
\hline Primary level & $79(18.7)$ & $68(16.1)$ & $1.3(0.634,2.64)$ & $1.4(0.6,3.0)$ \\
\hline Secondary level & $43(10.2)$ & $52(12.3)$ & $1.8(0.86,3.8)$ & $2.2(1.0,5.2)$ \\
\hline Tertiary level & $44(10.4)$ & $96(22.8)$ & $3.3(1.6,6.8)$ & $4.3(1.9,9.8)^{* *}$ \\
\hline \multicolumn{5}{|l|}{ Occupational status } \\
\hline Unemployed & 65 & 64 & 1.0 & 1.0 \\
\hline Employed & 125 & 168 & $1.4(0.8,2.1)$ & $0.9(0.6,1.5)$ \\
\hline \multicolumn{5}{|c|}{ Average monthly income of respondent's family or friends (ETB) } \\
\hline$<585$ & $85(20.1)$ & $81(19.2)$ & $0.6(0.4,1.1)$ & $0.5(0.2,1.3)$ \\
\hline $586-1650$ & $30(7.1)$ & $36(8.5)$ & $0.4(0.2,0.7)$ & $0.4(0.2,0.9)^{*}$ \\
\hline $1651-3145$ & $39(9.2)$ & $44(10.4)$ & $0.4(0.23,0.7)$ & $0.6(0.3,1.3)$ \\
\hline$\geq 3146$ & $35(8.3)$ & $70(16.6)$ & 1.0 & 1.0 \\
\hline \multicolumn{5}{|l|}{ Sleeping practice in your home } \\
\hline Alone and separate room & $69(16.4)$ & $120(28.4)$ & $3.5(2.14,5.65)$ & $8.0(4.0,15.7)^{* *}$ \\
\hline Alone but not separate room & $43(10.2)$ & $73(17.3)$ & $3.4(2.0,5.82)$ & $5.8(2.9,11.2)^{* *}$ \\
\hline In one bed with other members of family or friends & $78(18.5)$ & $39(9.3)$ & 1.0 & 1.0 \\
\hline \multicolumn{5}{|l|}{ No. of family/friends live with TB patients } \\
\hline No one with me & $39(9.2)$ & $63(14.9)$ & $1.7(1.01,2.8)$ & $1.9(0.7,4.5)$ \\
\hline 2-3 members & $69(16.4)$ & $90(21.3)$ & $1.2(0.7,1.9)$ & $1.2(0.6,2.2)$ \\
\hline$\geq 4$ members & $82(19.4)$ & 79 (18.7) & 1.0 & 1.0 \\
\hline
\end{tabular}

${ }^{*}$ indicates statistical significance association $b / n$ independent and dependent variable. ${ }^{* *}$ indicates statistical strongly significance association $b / n$ independent and dependent variables. ${ }^{*}$ indicates percentage sum was more than $100 \%$ because of multiple responses and think that there are missed value in variables.

water. The study also showed that $195(46.2 \%)$ of TB patients expressed their agreement that someone can acquire MDRTB through drinking alcohol or smoking. Regarding the treatment of MDR-TB, 102 (24\%) of the respondents agreed that taking traditional medicines can cure MDR-TB and 296 (70.1\%). The patients revealed that taking TB treatment under direct observation of health professionals is an important way to prevent the development of MDR-TB. Also, 102 (24\%) respondents agreed that someone could stop taking TB treatment when he/she feels better while $141(33.4 \%)$ agreed that the treatment of TB should be stopped when they encountered side effects of the drug. From all studied participants, 192 (45.5\%) of TB patients agreed that the MDR-TB is caused by human activities and $321(76.1 \%)$ of the TB patients agreed that increasing the prevalence of MDR-TB in Ethiopia has high impact in social, political, and economic development. On the other hand, 273 (64.7) of TB patients agreed that MDR-TB is a highly infectious and contagious disease (Table 4).

The study showed that the mean attitude scored of TB patients was $6 \pm 0.4$. One hundred twelve $(26.5 \%)$ of $\mathrm{TB}$ patients scored below the mean and had unfavourable attitudes about MDR-TB. Multivariate analysis results also revealed that there was a significant relationship between the attitude of MDR-TB and occupational status of respondents where those who were unemployed had more unfavourable attitudes towards MDR-TB (AOR $=4.4,95 \%$ $\mathrm{CI}=2.5,7.6)$ compared to employed ones. Respondents who sleep alone in a separate room had a favourable attitude $(\mathrm{AOR}=2.4,95 \% \mathrm{CI}=1.2,5.0)$ as compared to $\mathrm{TB}$ patients 
TABLE 4: Frequency and percent of attitude measuring variables of TB patients about MDR-TB, Addis Ababa, Ethiopia, 2016 ( $N=422$ ).

\begin{tabular}{|c|c|c|c|}
\hline Characteristics & Agree & Neutral & Disagree \\
\hline There was fear of discrimination due to TB patient & $160(37.9 \%)$ & $19(4.5 \%)$ & $243(57.6 \%)$ \\
\hline The cause of MDR-TB is man-made & $192(45.5 \%)$ & $26(6.2 \%)$ & $204(48.3)$ \\
\hline MDR-TB can be treated by praying or by holy water & $150(35.5 \%)$ & $38(9 \%)$ & $234(55.5 \%)$ \\
\hline $\begin{array}{l}\text { People can acquire MDR-TB through drinking alcohol } \\
\text { and/or smoking cigarette }\end{array}$ & $195(46.2 \%)$ & $38(9 \%)$ & $189(44.8 \%)$ \\
\hline $\begin{array}{l}\text { Covering mouth and nose by the mask is one way of } \\
\text { protecting the transmission of MDR-TB to other people }\end{array}$ & 337 (79.9\%) & $11(2.6 \%)$ & 74 (17.5\%) \\
\hline Taking traditional medicines can cure MDR-TB & $102(24 \%)$ & $36(8.5 \%)$ & $284(67.3 \%)$ \\
\hline $\begin{array}{l}\text { Increasing the prevalence of MDR-TB in Ethiopia has a } \\
\text { high impact on social, political, and economic development }\end{array}$ & $321(76.1 \%)$ & $25(5.9 \%)$ & $76(18 \%)$ \\
\hline Someone can stop taking anti-TB drugs when he/she feels better & $102(24.2 \%)$ & $14(3.3 \%)$ & $306(72.5 \%)$ \\
\hline People do not respect you; if you are MDR-TB patient/client & $149(35.3 \%)$ & $25(5.9 \%)$ & $248(58.8 \%)$ \\
\hline $\begin{array}{l}\text { Someone can stop MDR-TB treatment when s/he encountered } \\
\text { with the side effect of the drugs }\end{array}$ & $141(33.4 \%)$ & $23(5.5 \%)$ & $258(61.1 \%)$ \\
\hline $\begin{array}{l}\text { Taking TB treatment by direct observation of health personnel is } \\
\text { an important way to prevent development MDR-TB. }\end{array}$ & $296(70.1 \%)$ & $23(5.5 \%)$ & $103(24.4)$ \\
\hline $\begin{array}{l}\text { Multidrug resistance tuberculosis is a highly infectious and } \\
\text { contagious disease. }\end{array}$ & $273(64.7 \%)$ & $13(3.1 \%)$ & $136(32.2 \%)$ \\
\hline
\end{tabular}

who sleep in one bed with his/her family or friends. The study also showed a significant relationship between the attitude of respondents about MDR-TB and monthly family income. TB patients with an average monthly family income of less than or equal to 585 Ethiopian Birr (AOR $=2.0,95 \%$ $\mathrm{CI}=1.03,3.9)$ and 586-1650 Ethiopian Birr (AOR $=2.9,95$ $\% \mathrm{CI}: 1.2,6.6)$ had more favourable attitudes than those who had a monthly family income of $\geq 3146$ Ethiopian Birr. On the other hand, the attitude of respondents about MDR-TB was not significantly associated with gender, marital status, and educational status of TB patients (Table 5).

\section{Discussion}

From 422 TB patients, only 284 (67.9\%) TB patients ever heard about MDR-TB, and of these, only $178(62.7 \%)$ of them heard it from healthcare professionals which are less than a study conducted in Southwest Ethiopia in which $83 \%$ of TB patients heard about MDR-TB. This could be due to the insufficiency in the provision of health education about MDR-TB that should be given to all health centres, and TB patients might also assume themselves as knowledgeable [16]. Additionally, healthcare professionals' poor knowledge about MDR-TB might contribute to lower patient knowledge about the disease as they may convey inadequate and incomplete information about the disease and treatment regimen $[10,17]$.

In this study, the overall knowledge of TB patients was not satisfactory as only $55 \%$ of TB patients had good knowledge about MDR-TB. This was not unexpected because many studies in Africa and other parts of the world have documented that TB patients lack basic knowledge of aetiology, transmission, prevention, and duration of treatment of MDR-TB [17-19], but it is better than the study conducted in Nigeria in which only $18.4 \%$ of patients had good knowledge of MDR-TB [10]. The poor knowledge of TB patients is inimical to the control of the disease in any population. It is also a common practice for patients to seek information from other sources like neighbours, traditional healers, and churches. This at times might worsen their condition by creating the wrong perception about the disease and unsubstantiated health-seeking behaviours. In the case of TB, it has been shown in many studies that poor knowledge and wrong perceptions were responsible for the delay in seeking health care in a health facility, treatment default, and stigmatization of TB patients $[4,18,20,21]$. All these were contributing factors for the rising prevalence of MDR-TB, and this poses a major challenge to many National TB Control Programs. Thus, the Federal Ministry of Health and other stakeholders should make a concerted effort to strengthen the provision of education during the DOT period and organize awareness creation campaigns to improve the knowledge and attitude of TB patients.

The finding of this study revealed that the level of knowledge about MDR-TB was positively associated with the educational status of TB patients. The odd of good knowledge in TB patients attended tertiary level of education was 4.3 times higher than the odds of TB patients who did not attend any level of education or illiterates. This was attributed to relatively better awareness about MDR-TB and better access to health information in those attended tertiary level of education (28.4\%) in Addis Ababa, Ethiopia, compared with a study conducted in Delta state, Nigeria (19.7\%), and the study conducted in Ulaanbaatar $(53.9 \%$ of patients did not know about TB) $[10,11]$.

In this study, knowledge had a significant association with the sleeping practice of studied participants. The present study demonstrated that the likelihood of having good knowledge was 1.3 times higher in those patients who sleep alone in a separate room than respondents who shared a bedroom with his/her family or friends. On the contrary, a study conducted in Yangon Myanmar found that $96.3 \%$ of patients 
TABle 5: TB patients overall attitudes and associated factors on MDR-TB in Addis Ababa, Ethiopia, $2016(N=422)$.

\begin{tabular}{|c|c|c|c|c|}
\hline \multirow{2}{*}{ Characteristics } & \multicolumn{2}{|c|}{ Overall attitude $(n(\%))$} & \multirow{2}{*}{ Crude (COR) } & \multirow{2}{*}{ Adjusted (AOR) } \\
\hline & Unfavourable & Favourable & & \\
\hline \multicolumn{5}{|l|}{ Sex } \\
\hline Male & $54(12.8)$ & $163(38.6)$ & 1.0 & 1.0 \\
\hline Female & $58(13.7)$ & $147(34.8)$ & $1.2(0.7,1.8)$ & $1.2(0.7,1.9)$ \\
\hline \multicolumn{5}{|l|}{ Age (years) } \\
\hline$\leq 34$ & $68(16.1)$ & $212(50.2)$ & $3.1(0.7,13.4)$ & $2.9(0.6,12.8)$ \\
\hline $35-54$ & $39(9.2)$ & $76(18.0)$ & $4.9(1.1,22.0)$ & $4.8(1.1,22.1) *$ \\
\hline$\geq 55$ & $2(0.5)$ & $19(4.5)$ & 1.0 & 1.0 \\
\hline \multicolumn{5}{|l|}{ Marital status } \\
\hline Never married & $54(12.8)$ & $153(36.3)$ & 1.0 & 1.0 \\
\hline Ever married & $57(13.5)$ & $157(37.2)$ & $1.1(0.67,1.6)$ & $0.9(0.5,1.4)$ \\
\hline \multicolumn{5}{|l|}{ Educational status } \\
\hline None (illiterate) & $14(3.3)$ & $26(6.2)$ & $1.3(0.6,2.6)$ & $1.2(0.5,2.7)$ \\
\hline Primary level & $34(8.1)$ & $113(26.8)$ & $0.7(0.4,1.1)$ & $0.7(0.4,1.2)$ \\
\hline Secondary level & $22(5.2)$ & $73(17.3)$ & $0.7(0.4,1.3)$ & $0.6(0.3,1.2)$ \\
\hline Tertiary level & $42(9.9)$ & $98(23.2)$ & 1.0 & 1.0 \\
\hline \multicolumn{5}{|l|}{ Occupational status } \\
\hline Unemployed & $53(12.6)$ & $76(18.0)$ & $3.1(1.9,5.1)$ & $4.4(2.5,7.6)^{* *}$ \\
\hline Employed & $59(13.9)$ & $65(15.5)$ & 1.0 & 1.0 \\
\hline \multicolumn{5}{|l|}{ Average monthly income of respondents' family or friends } \\
\hline$\leq 585$ & $50(11.8)$ & $125(29.5)$ & $1.7(0.9,3.1)$ & $2.0(1.03,3.9)^{*}$ \\
\hline $586-1650$ & $22(5.2)$ & $36(8.5)$ & $2.6(1.3,5.3)$ & $2.9(1.2,6.6)^{*}$ \\
\hline $1651-3145$ & $19(4.5)$ & $63(14.9)$ & $1.3(0.6,2.6)$ & $1.5(0.6,3.2)$ \\
\hline$>3146$ & $20(4.8)$ & $85(20.1)$ & 1.0 & 1.0 \\
\hline \multicolumn{5}{|l|}{ Sleeping practice in your home } \\
\hline Alone and separate room & $44(10.4)$ & $145(34.4)$ & 1.0 & 1.0 \\
\hline Alone but not separate room & $28(6.6)$ & $88(20.8)$ & $1.1(0.6,1.8)$ & $1.2(0.7,2.2)$ \\
\hline In one bed with other members of family or friends & $40(9.6)$ & $77(18.2)$ & $1.7(1.03,2.9)$ & $2.4(1.2,5.0)^{*}$ \\
\hline \multicolumn{5}{|l|}{ No. of family/friends live with TB patients } \\
\hline No one with me & $25(5.9)$ & $77(18.3)$ & 1.0 & 1.0 \\
\hline Family/friends size is $2-4$ & $69(16.4)$ & $175(41.5)$ & $1.2(0.7,2.1)$ & $1.3(0.6,3.5)$ \\
\hline Family/friends size $\geq 5$ & $18(4.3)$ & $58(13.7)$ & $0.96(0.5,1.92)$ & $0.9(0.3,2.4)$ \\
\hline
\end{tabular}

${ }^{*}$ indicates statistical significance association $b / n$ independent and dependent variable. ${ }^{* *}$ indicates statistical strongly significance association $b / n$ independent and dependent variable.

did not sleep with family members under the same net [22]. The current findings might be due to a lack of awareness and knowledge about the mode of transmission and ways of prevention of MDR-TB. This fact has been supported by the present finding where $65(15 \%)$ of the study participants mentioned that TB cannot be transmitted by inhalation of an infected droplet from person to person and 80 (18.9\%) of them also wrongly mentioned that TB can be transmitted via blood and sexual contacts.

From $422 \mathrm{~TB}$ patients, more than one-fourth (26.5\%) have unfavourable attitudes towards MDR-TB whereas $32.5 \%$ were confirmed in the study conducted in Delta state, Nigeria [9]. The attitude developed among the people could be the reason for defaulting anti-TB drug, stop MDR-TB treatment due to minor side effect, stop taking TB treatment drug when he/she feels better, and take traditional medicines to cure of MDR-TB.

In this study, 205 (48.5\%) of TB patients disagreed by the cause of MDR-TB is man-made and 150 (35.5\%) respondents believed that MDR-TB is treated by praying or by holy water. This indicated that TB patients have misconceptions, creating wrong perception, and negative health-seeking behaviours about MDR-TB [10].

In the current study, $321(76.1 \%)$ respondents agreed that increasing the prevalence of MDR-TB in Ethiopia has a high impact in social, political, and economic development, whereas $76(18.0 \%)$ respondents did not agree. The 296 (70.1\%) respondents agreed on taking TB treatment by direct observation of health personnel is an important way of developing MDR-TB which has a less favourable attitude about 
MDR-TB compared with the study conducted on Amhara region in Ethiopia showed that 95.7\% [23].

From all TB patients who have the favourable attitude, $177(57.1 \%)$ TB patients have not heard about the disease from health care workers which revealed inadequate or incomplete information passed on to the TB patients by HCWs would create wrong perceptions in them or strengthen the patients' perceptions which were similar with the study conducted by Delta State, Nigeria [10], to solve this preparation of IEC and BCC materials and expanding IEC activities using the TB patients concerning MDR-TB. So those TB patients use as cadres to advocate about MDR-TB.

\section{Limitations and Strengths}

The limitation of this study; the research was conducted only on patients who were diagnosed and taking anti-TB treatment on the DOT program and not measuring the practice of TB patients. The strength of the study; the project was focused on different subcities and health centres with trying to address patients' related factors influencing MDR-TB prevention and control strategies.

\section{Conclusion}

This study identified that the knowledge of TB patients toward MDR-TB was poor (45\%), one-third of TB patients (33.0\%) never heard about MDR-TB, and two-third $(62.7 \%)$ of TB patients heard from health workers and the number of studied patients also showed unfavourable attitude (26.5\%) towards MDR-TB in Addis Ababa, Ethiopia.

The different factors which affect the knowledge and attitude of TB patients about MDR-TB were occupational status, average monthly income, sleeping practices, educational status, and others. Subsequently, it is essential to improve the living condition of TB patients, and efforts should be made to implement health education to improve awareness of TB patients about MDR-TB.

\section{Abbreviations}

BCC: Behavior change communication

DOT: Direct observation therapy

DR-TB: Drug resistance tuberculosis

ETB: $\quad$ Ethiopian birr

HCWs: Health care workers

IEC: Information education and communication

MDR-TB: Multidrug resistance tuberculosis

TB: Tuberculosis

WHO: World Health Organization.

\section{Data Availability}

Data supporting the findings can be found in the Tables.

\section{Additional Points}

Statement of the Author. We hereby declare and affirm that this thesis is our work. All scholarly matter that is included in the thesis has been given recognition through citation.

\section{Conflicts of Interest}

The authors declare that they have no conflicts of interest.

\section{Authors' Contributions}

FT and GB designed this study. FT collected the data. FT and GB analyzed and interpreted data. FT drafted the manuscript. FT, GB, and TM contributed to further drafts the manuscript. All authors read and approved the final manuscript.

\section{Acknowledgments}

We thank the study participants, data collectors, health centres from different subcities, and research assistants.

\section{References}

[1] M. Raviglione and G. Sulis, "Tuberculosis 2015: burden, challenges and strategy for control and elimination," Infectious Disease Reports, vol. 8, no. 2, pp. 33-37, 2016.

[2] WHO, Global Tuberculosis Report 2016, 2016.

[3] A. H. Kebede, Z. Alebachew, F. Tsegaye et al., "The first population-based national tuberculosis prevalence survey in Ethiopia, 2010-2011," The International Journal of Tuberculosis and Lung Disease, vol. 18, no. 6, pp. 635-639, 2014.

[4] World Health Organization, Global tuberculosis report 2018, World Health Organization, 2018.

[5] Federal MinistryHealth ethiopia, Tuberculosis, Leprosy and TB/HIV Prevention and Control Programme. Vol. Manual Fou, 2008.

[6] A. Esmael, I. Ali, M. Agonafir, A. Desale, Z. Yaregal, and K. Desta, "Assessment of patients' knowledge, attitude, and practice regarding pulmonary tuberculosis in Eastern Amhara Regional State, Ethiopia: Cross-Sectional study," The American Journal of Tropical Medicine and Hygiene, vol. 88, no. 4, pp. 785-788, 2013.

[7] FMOH, Guidelines on Programmatic Management of Drug Resistant Tuberculosis in Ethiopia, Addis Ababa, 2013.

[8] WHO, Companion handbook to the WHO guidelines for the programmatic management of drug-resistant tuberculosis, World Health Organization, 2014.

[9] N. Malangu and O. D. Adebanjo, "Knowledge and practices about multidrug-resistant tuberculosis amongst healthcare workers in Maseru," African Journal of Primary Health Care \& Family Medicine, vol. 7, no. 1, pp. 1-5, 2015.

[10] A. R. Isara and A. Akpodiete, "Concerns about the knowledge and attitude of multidrug-resistant tuberculosis among health care workers and patients in Delta State, Nigeria," Nigerian Journal of Clinical Practice, vol. 18, no. 5, pp. 664-669, 2015.

[11] A. S. Kasa, A. Minibel, and G. M. Bantie, "Knowledge, attitude and preventive practice towards tuberculosis among clients visiting public health facilities," BMC Research Notes, vol. 12, no. 1, p. 276, 2019.

[12] D. Tolossa, G. Medhin, and M. Legesse, "Community knowledge, attitude, and practices towards tuberculosis in Shinile town, Somali regional state, eastern Ethiopia: a crosssectional study," BMC Public Health, vol. 14, no. 1, pp. 1-13, 2014. 
[13] L. Liang, Q. Wu, L. Gao et al., "Factors contributing to the high prevalence of multidrug-resistant tuberculosis: a study from China," Thorax, vol. 67, no. 7, pp. 632-638, 2012.

[14] Federal Ministry of Health, Health and Health Related Indicators 2005 E . C (2012 / 2013). Vol. 2, Health and Health Related indicators, $2005 \mathrm{EFY}, 2014$.

[15] C. R. Kothari, Research methodology methods and techniques, New Age Iternational Publishers, Second edition, 2004.

[16] G. Abebe, A. Deribew, L. Apers et al., "Knowledge, health seeking behavior and perceived stigma towards tuberculosis among tuberculosis suspects in a rural community in Southwest Ethiopia," PLoS One, vol. 5, no. 10, pp. 1-7, 2010.

[17] L. P. Ormerod, "Multidrug-resistant tuberculosis (MDR-TB): epidemiology, prevention and treatment," British Medical Bulletin, vol. 73-74, pp. 17-24, 2005.

[18] J. A. Khan, M. Irfan, A. Zaki, M. Beg, S. F. Hussain, and N. Rizvi, "Knowledge, attitude and misconceptions regarding tuberculosis in Pakistani patients," The Journal of the Pakistan Medical Association, vol. 56, no. 5, pp. 211-214, 2006.

[19] F. A. D. Kaona, M. Tuba, S. Siziya, and L. Sikaona, "An assessment of factors contributing to treatment adherence and knowledge of TB transmission among patients on TB treatment," BMC Public Health, vol. 4, pp. 1-8, 2004.

[20] E. Tobin, P. W. Okojie, and E. Isah, "Community knowledge and attitude to pulmonary tuberculosis in rural Edo state, Nigeria," Annals of African Medicine, vol. 12, no. 3, pp. 148154, 2013.

[21] R. Shrestha-Kuwahara, M. Wilce, H. A. Joseph, J. W. Carey, R. Plank, and ESI, Tuberculosis Research and Control, Anthropological Contributions, vol. 1, pp. 528-542, 2004.

[22] T. E. Fana, E. Ijeoma, and L. Sotana, "Knowledge, attitudes, and prevention practices of drug resistant tuberculosis in the Eastern Cape Province, South Africa," Tuberculosis Research and Treatment, vol. 2019, 12 pages, 2019.

[23] S. Yimer, C. Holm-hansen, T. Yimaldu, and G. Bjune, "Health care seeking among pulmonary tuberculosis suspects and patients in rural Ethiopia : a community-based study," BMC Public Health, vol. 9, pp. 1-9, 2009. 